\title{
Phenolic Content and Antioxidant and Antimicrobial Activities of Malva sylvestris L., Malva oxyloba Boiss., Malva parviflora L., and Malva aegyptia L. Leaves Extract
}

\author{
Khalid A. Shadid $\mathbb{D}^{1,2}$ Ashok K. Shakya ${ }^{1 D},{ }^{1,2}$ Rajashri R. Naik $\mathbb{D}^{1,2}$ Nidal Jaradat $\left(\mathbb{D},{ }^{3}\right.$ \\ Husni S. Farah $\mathbb{D}^{2,4}$ Naeem Shalan $\mathbb{D}^{1,2}$ Nooman A. Khalaf $\mathbb{D},{ }^{1,2}$ and Ghaleb A. Oriquat $\mathbb{D}^{2,4}$ \\ ${ }^{1}$ Faculty of Pharmacy, Al-Ahliyya Amman University, Amman, Jordan \\ ${ }^{2}$ Pharmaceutical and Diagnostic Research Centre, Al-Ahliyya Amman University, Amman, Jordan \\ ${ }^{3}$ Department of Pharmacy, An-Najah National University, P.O. Box 7, Nablus, State of Palestine \\ ${ }^{4}$ Faculty of Allied Medical Sciences, Al-Ahliyya Amman University, Amman, Jordan
}

Correspondence should be addressed to Khalid A. Shadid; kshadid@ammanu.edu.jo

Received 22 September 2020; Revised 23 December 2020; Accepted 11 March 2021; Published 28 March 2021

Academic Editor: Ajaya Kumar Singh

Copyright $\odot 2021$ Khalid A. Shadid et al. This is an open access article distributed under the Creative Commons Attribution License, which permits unrestricted use, distribution, and reproduction in any medium, provided the original work is properly cited.

Background. The plants brought by Arabs were of real therapeutic values. Ibn Al-Baitar, an Islamic scholar (pharmacist, botanist, and physician), in his encyclopedia wrote the detailed characterization of more than one thousand herbs describing their medicinal value, methods of preparation, and their route of administration. Objectives. The current investigation points towards the quantitative characterization of the phenolic contents among the four edible Malva plants species (Malva sylvestris L., Malva oxyloba Boiss., Malva parviflora L., and Malva aegyptia L.) and also towards assessing their antibacterial activity against one Gram-positive isolate (Staphylococcus aureus) and four Gram-negative strains Escherichia coli, Pseudomonas aeruginosa, Shigella sonnei, and Proteus vulgaris. It also aimed to evaluate the free radical scavenging activity of hexane, methanolic, aqueous, and acetone extracts of four Malva species. Methods. By utilizing the Folin-Ciocalteu procedure and gallic acid as a reference molecule, the phenolic contents were estimated. In addition, the broth microdilution method was used to evaluate four plants' 16 extracts, and the DPPH (2,2-diphenyl-1-picrylhydrazyl) method was utilized to assess the abovementioned extracts against oxidative stress. Results. The results showed that the methanolic extract of M. oxyloba has the highest contents of phenols $(191.54 \pm 2.84 \mathrm{mg}$ of $\mathrm{GAE} / \mathrm{g})$ and has the best antioxidant capacity with an $\mathrm{IC}_{50}$ value of $1.94 \pm 1.84 \mu \mathrm{g} / \mathrm{ml}$, which is very close to Trolox. Regarding the ferrous ion chelating activity of the extract, the methanolic extract of $M$. sylvestris exhibits appreciable activity with $\mathrm{IC}_{50}$ values of $52.7 \pm 1.8 \mu \mathrm{g} / \mathrm{ml}$. In addition, the plant extract and acetone extract of M. sylvestris showed a strong antibacterial activity with an MIC value of $0.0078 \mathrm{mg} / \mathrm{ml}$. Conclusion. The methanolic extract of $M$. oxyloba has a pharmacological potential as a valuable natural product that can be utilized as a main ingredient in the design and development of new therapeutic formulations. It exerts multiple inhibitory properties against oxidative stress and bacterial growth. As such, it is emerging as a promising therapeutic agent for the treatment of various neurodegenerative diseases and many types of human infectious diseases.

\section{Introduction}

The history of phytotherapy started with our ancestors, who had the knowledge of the herbs and knew that the consumption of certain kinds of herb resulted in the soothing effect of several types of diseases. Recently, herbal remedies have become a controversial issue all over the world as large numbers of herbals are utilized in large quantities in cosmetics, as food preservatives and as nutritional supplements and as natural ingredient in large number of drugs in many of the pharmaceutical industries. In fact, people around the world are more moving towards or prefer the herbal medicines due to the belief that these phytotherapeutic products are natural and safer than synthetic medicines [1]. In recent years, the term oxidative stress has been gaining interest among many research scientists, and this has led to the development of numerous techniques in the prevention of diseases caused by the action of the harmful free radicals that 
cause oxidative stress. In addition, they studied the possible roles of antioxidants in protecting the body from many dangerous diseases caused due to oxidative stress. Common free radical such as hydroxyl $(\mathrm{OH})$, superoxide $\left(\mathrm{O}^{2-}\right)$, and nitric monoxide $\left(\mathrm{NO}^{-}\right)$are considered as causative agents for many chronic diseases such as cancer, diabetes, cardiovascular diseases, rheumatoid arthritis, and other oxidative diseases. At the same time, there are many antioxidant compounds, mostly probably derived from plants, such as vitamin $\mathrm{E}$, vitamin $\mathrm{C}$, creatinine, and other phenolic compounds have the ability to protect the body against the diseases caused by free radicals [2].

It has been observed that the bacterial strains are being increasingly resistant to the antibiotics that are available in the market due to their overuse. The available reports suggest that the overuse of the antiseptic in house and hospitals also contributed to the increase in the resistance of bacteria. However, if the patients with bacterial infection, that is, resistance to antibiotics, did not receive effective treatment may lead to long-term infections that may result in high mortality as was observed in the patients with pneumococcal infections and typhoid fever [3].

Malva (Malvaceae family) is a very common plant growing in wildly in the Middle Eastern countries and commonly known as mallow and has been used by Greek and Romans as an emollient and laxative; also, it has been used to treat some diseases associated with alimentary canal and respiratory disorders. In Asian countries, it is used to treat injuries and inflammations. People use Malva species in different ways; many use it in their food; they eat it raw mixed in a salad or cooked as a vegetable. Other people use its flowers for medicinal purpose to treat injuries and different skin disorders [4]. The intensive use of Malva species among Arabian population urges us to study and identify the medical and chemical characteristics of Malva sylvestris L., Malva oxyloba Boiss., Malva parviflora L., and Malva aegyptia L.

Malva sylvestris is used as a folkloric food and has traditional medicine particularly in the treatment of dermatitis, peptic ulcer, cough, diabetes, and sore throat [5]. It contains tannins, vitamins (A, C, and E), folic acid, niacin, polyphenols (anthocyanins), scopoletin, malvone A (2methyl-3-methoxy-5,6-dihydroxy-1,4-naphthoquinone) malvaline, malvidin 3-(6" -malonyl -glucoside)-5-glucoside, malvin, flavonoids (three 8-hydroxyflavonoids, hypolaetin $3^{\prime}$-sulphate, and gossypetin 3 -sulphate-8-O- $\beta$-D-glucoside) polysaccharides (mucilage) and coumarins [6].

In a study established by Tabaraki et al., they identified the bioactive molecule from Malva sylvestris using GC-MS technique and found that the major compound in the methanolic extract was 2-methoxy-4-vinylphenol [7]. Moreover, $M$. sylvestris anthocyanins contents reduced plasma total triglycerides and cholesterol and also protected rats from ethanolinduced gastritis due to the high contents of mucilage [8-10].

Hot poultice of Malva parviflora used in traditional medicine to treat wounds, swelling, sores, bruises, and broken limbs. It contains tannin, flavonoid, polyphenol, saponin, resin, and alkaloid. Several investigations showed that M. parviflora has antiulcerogenic, analgesic, antidiabetic, anti-inflammatory, antibacterial, and neuroprotective activities [11]. Throughout the literature, no previous studies were carried out to investigate the constituents and the pharmacological activities of M. oxyloba and M. aegyptia. This prompted us to search for new source of safer and inexpensive antioxidants from four edible species of $M$. sylvestris, $M$. oxyloba, M. parviflora, and $M$. aegyptia plants. The extracts were prepared in aqueous solution, hexane, acetone, and methanol solvent; these extracts were tested for their antioxidant activity using DPPH method, and to estimate their total phenol contents using the Folin-Ciocalteu assay, the relationship between antioxidant activity and total phenol contents was correlated; their antimicrobial properties were also studied.

\section{Materials and Methods}

2.1. Chemicals. Trolox (6-hydroxy-2,5,7,8-tetramethylchroman-2-carboxylic acid) was purchased from Sigma Aldrich company (Denmark), DPPH (2,2-diphenyl-1-picrylhydrazyl), Folin-Ciocalteu, and Ferrozine reagent were brought from Sigma Aldrich (Germany), while methanol, hexane, and acetone were obtained from Loba Chemie (India). Moreover, dimethyl sulfoxide (DMSO) was brought from Riedel-de Haën (Germany); Mueller-Hinton (Dickinson, USA) and nutrient broth were purchased from HiMedia (India).

2.2. Instruments. Shaker device (Memmert, Germany), rotavap (Heidolph-OB2000, Germany), UV-Visible spectrophotometer (Jenway-7315, England), UV-Visible spectrophotometer (Shimadzu, Japan) Balance (Radwag-AS 220/ $\mathrm{c} / 2$, Poland, and Shimadzu, Japan), grinder (Molineux N-1, China), filter papers (Macherey-Nagel-MN 617 and Whatman no.1, USA), micropipettes (Finnpipette, Finland), incubator (Nuve-Model 002, Turkey), syringe filter $0.45 \mu \mathrm{m}$ pore size (Microlab, China), 96-well plates (Greiner BioOne, North America), and multichannel micropipette (Thermo Fisher Scientific, DE, Germany).

2.3. Collection and Preparation of Plants. The leaves of M. sylvestris, M. oxyloba, M. parviflora, and M. aegyptia plants were collected in March 2018 during the flowering time from Tulkarm plains and mountains in the West Bank area of Palestine. The four Malva species were identified in the pharmacognosy and herbs laboratory, Faculty of Medicine and Health Sciences, An-Najah National University, Nablus, State of Palestine. The herbarium voucher specimen stored in the Pharmacognosy Laboratory under the following codes: Pharm-PCT-1507, Pharm-PCT-1505, PharmPCT-1506, and Pharm-PCT-1502.

The leaves of each of the Malva species were washed with distilled water and then dried separately at room temperature. The drying took about 2-3 weeks until all the four plants species materials were well dried. By using the grinder, the dried parts for each type were grounded well, and the material powders were kept under dry condition ready for further use.

2.4. Extraction. The exhaustive maceration was used to extract $M$. sylvestris, $M$. oxyloba, M. parviflora, and $M$. aegyptia plants materials by soaking $150 \mathrm{~g}$ of powdered 
samples sequentially into $500 \mathrm{ml}$ of distilled water, $n$-hexane, ethyl acetate, and methanol in an enclosed glass bottle with occasional shaking at room temperature for $72 \mathrm{hrs}$.

Thereafter, the macerated materials were then filtered through a Whatman No. 1 filter paper and then evaporated under reduced pressure in a rotary evaporator set at $35^{\circ} \mathrm{C}$ in a water bath until the solvents completely evaporated, while the aqueous extracts were freeze-dried. The final dried extracts were stored at $4^{\circ} \mathrm{C}$ in a refrigerator.

2.5. Total Phenol Content. The total phenol contents of M. sylvestris, M. oxyloba, M. parviflora, and M. aegyptia plants four extracts were estimated calorimetrically utilizing the Folin-Ciocalteu procedure and gallic acid as a reference molecule [12-14]. Briefly, from each plant fraction, $1 \mathrm{mg} / \mathrm{ml}$ aqueous solution was prepared for this analysis, while the reaction mixtures were prepared by taking $0.5 \mathrm{ml}$ of the aqueous solution from each plant fraction, $2.5 \mathrm{ml}$ of $10 \%$ Folin-Ciocalteu's testing agent dissolved in water, and $2.5 \mathrm{ml}$ of $7.5 \% \mathrm{NaHCO}_{3}$ in aqueous solution. Thereafter, the produced mixtures were kept in a thermostat at $45^{\circ} \mathrm{C}$ for $45 \mathrm{~min}$. The absorbance was estimated utilizing a spectrophotometer at a wavelength of $765 \mathrm{~nm}$. All of the studied samples were tested in triplicate for each plant fraction, and the mean values of absorbance obtained were reported. The same method was repeated for the standard molecule gallic acid, and then the required calibration curve was constructed. Based on the measured absorbance, the concentration of gallic acid equivalent was determined in $\mathrm{mg}$ of GAEq/g for each working plant sample.

2.6. Free Radical Scavenging DPPH Method. According to the method described by Jothy et al. [15] with some modifications, the antioxidant activity was determined using DPPH scavenging assay. A stock solution of Trolox and 16 plant extracts in methanol was prepared with a concentration of $1 \mathrm{mg} / \mathrm{mL}$; from the stock solution by serial dilution method, various concentrations were prepared. Then, $0.002 \% \mathrm{DPPH}$ was prepared. A concentration ratio (1:1:1) of the above prepared solution, DPPH, and methanol were arranged, respectively. These solutions were incubated in a dark place for $30 \mathrm{~min}$, while methanol was utilized to zero the UV-Vis-spectrophotometer. Then, the absorbance readings were measured at $517 \mathrm{~nm}$. Antioxidant activity is given as percent DPPH scavenging that is calculated as

$$
\% \mathrm{DPPH} \text { scavenging }=\frac{\mathrm{M}-\mathrm{S}}{\mathrm{M}} X 100 \% \text {, }
$$

where $\mathrm{M}$ is the absorbance of the control sample and $\mathrm{S}$ is the absorbance of the tested extracts. The results are documented as an $\mathrm{IC}_{50}$ value which is the inhibitory concentration required to decrease $50 \%$ of the activity.

2.7. Ferrous Ion-Chelating Activity. The samples were estimated for the ferrous ion-chelating activity as described by Chua et al. [16] Briefly, $750 \mu \mathrm{L}$ of the sample in test material $(2-500 \mu \mathrm{g} / \mathrm{mL})$ or standard substance $(1-50 \mu \mathrm{g} / \mathrm{ml})$ were incubated with $50 \mu \mathrm{L}$ ferrous chloride solution $\left(\mathrm{FeCl}_{2}\right)$ $(2 \mathrm{mM})$ for $5 \mathrm{~min}$. The reaction was initiated by the addition of $50 \mu \mathrm{L}$ ferrozine solution $(5 \mathrm{mM})$ into the mixture and allowed to stand for 10 minutes in dark. The absorbance of the reaction mixture was measured at $562 \mathrm{~nm}$. All experiments were performed at least in triplicate. The chelating effect was calculated as a percentage using the following equation. EDTA was used as a positive control in this assay.

$$
\% \text { chelating activity }=\frac{\text { Acontrol }- \text { Asample }}{\text { Acontrol }} \times 100 \% \text {, }
$$

where Acontrol is the absorbance of the control reaction mixture without the test compounds, and Asample is the absorbance of the test compounds. IC $_{50}$ values, which represented the concentration of the extract that caused 50\% of $\mathrm{Fe}^{2+}$ ion chelation, were calculated from the plot of chelating percentage against concentration.

2.8. Microbial Isolates. The bacterial isolates were obtained from American-type culture collection (ATCC). The isolates included one Gram-positive strains: Staphylococcus aureus (ATCC-25923), in addition to four Gram-negative strains: Escherichia coli (ATCC-25922), Pseudomonas aeruginosa (ATCC-27853), Shigella sonnei (ATCC-25931), and Proteus vulgaris (ATCC-838).

2.9. Antimicrobial Test. For determination, the antimicrobial activity for four plants' 16 extracts, a micro broth dilution method was employed. Some colonies from the used bacterial pathogens were planted in agar broth for $24 \mathrm{hrs}$. A little amount of the bacteria was added inside a $5 \mathrm{ml}$ of Mueller-Hinton tube and was mixed. Then, the turbidity was compared with McFarland standard tube $0.5\left(1.5 \times 10^{8} \mathrm{cfu} /\right.$ $\mathrm{ml}$ ). Then, $2 \mathrm{ml}$ of the bacterial suspension was diluted with $4 \mathrm{ml}$ broth. The four Malva species extracts were prepared by dissolving $50 \mathrm{mg}$ of each in $1 \mathrm{ml}$ DMSO (100\%) with a $50 \mathrm{mg} /$ $\mathrm{ml}$ concentration. Then, $100 \mu \mathrm{l}$ from Mueller-Hinton was placed in a sterile 96-well microplate. By using a micropipette, a volume of $100 \mu \mathrm{l}$ of plant extracts was added into the first well and mixed. Serial dilution was done by transferring $100 \mu \mathrm{l}$ from well to next well up to well 11 from which $100 \mu \mathrm{l}$ was discharged after mixing process; well 12 had only broth without plants extracts, so bacterial growth will be noticed. However, a serial dilution was established under sterile conditions. After that, a $10 \mu \mathrm{l}$ of bacterial suspension was employed into all wells but not in well 11 . While well 12 must be turbid, if not we should know that something wrong happened with our media or bacteria. Then, the used microplate was incubated for $24 \mathrm{~h}$. Each plant extract was examined in duplicate. MIC is defined as the minimum concentration of the antibacterial agents that resulted in nonvisible turbidity compared with a control well.

2.10. Statistical Analysis. The extraction yields, total phenols, and antioxidant results of the four studied plant species were expressed as means \pm SD standard deviation. Statistics were compared utilizing unpaired $t$-tests. 
TABLe 1: Extractions yields percentages of four Malva species in water, hexane, methanol, and acetone.

\begin{tabular}{lcccc}
\hline Extracts & M. sylvestris, \% $( \pm \mathrm{SD})$ & M. oxyloba, \% $( \pm \mathrm{SD})$ & M. parviflora, \% $( \pm \mathrm{SD})$ & M. aegyptia, \% $( \pm \mathrm{SD})$ \\
\hline Aqueous & $3.25 \pm 0.75$ & $3.18 \pm 0.61$ & $2.91 \pm 0.55$ & $3.21 \pm 0.41$ \\
Hexane & $1.01 \pm 0.11$ & $0.97 \pm 0.15$ & $0.89 \pm 0.09$ & $0.74 \pm 0.05$ \\
Methanol & $4.31 \pm 0.97$ & $5.58 \pm 1.1$ & $3.88 \pm 0.89$ & $5.15 \pm 0.94$ \\
Acetone & $1.22 \pm 0.12$ & $0.98 \pm 0.09$ & $2.1 \pm 0.047$ & $1.74 \pm 0.65$ \\
\hline
\end{tabular}

\section{Results}

3.1. Plants Extract Yields. The obtained yields of M. sylvestris, M. oxyloba, M. parviflora, and M. aegyptia plants aqueous, hexane, methanol, and acetone solvents were calculated and performed in Table 1. The results showed that methanolic extracts of $M$. sylvestris, M. oxyloba, M. parviflora, and $M$. aegyptia have the highest extraction yields, which were $4.31 \pm 0.97,5.58 \pm 1.1,3.88 \pm 0.89$, and $5.15 \pm 0.94 \%$, respectively.

3.2. Phenolic Content. For the evaluation of total phenol content, the absorption values of several concentrations of the gallic acid standard are listed in Table 2. From the calibration curve of gallic acid (Figure 1), the following equation was used to estimate total phenol content in M. sylvestris, M. oxyloba, M. parviflora, and M. aegyptia plants aqueous, hexane, methanol, and acetone extracts [14].

$$
\begin{aligned}
y & =0.0112 x+0.0176, \\
r^{2} & =0.9956,
\end{aligned}
$$

where $y$ is the absorbance at $765 \mathrm{~nm}$ and $x$ is the total phenol content of the four Malva plants species various extracts.

Obviously, Table 3 indicates that acetone extract of $M$. sylvestris, the methanolic extract of $M$. oxyloba, and hexane extracts of $M$. aegyptia and M. parviflora plants have the highest total phenols among the other screened solvents.

3.3. Antioxidant Activity. The antioxidant activities of hexane, methanol, acetone, and aqueous $M$. sylvestris, M. oxyloba, M. parviflora, and M. aegyptia plants extracts were evaluated using DPPH free radical method. In addition, in the current study, Trolox, the powerful antioxidant compound, was used as a reference positive control. The DPPH inhibition effects for each studied Malva plant species are calculated in Tables 4-7 and shown in Figures 2-5. From Figures $2-5$, the $\mathrm{IC}_{50}$ values of hexane, methanol, acetone, and aqueous $M$. sylvestris, M. oxyloba, M. parviflora, and M. aegyptia plants extracts were calculated in addition to the Trolox standard $\left(\mathrm{IC}_{50}\right.$ value of $\left.1.86 \pm 0.8 \mu \mathrm{g} / \mathrm{ml}\right)$. These results are demonstrated in Table 8 , which showed that among $M$. sylvestris extracts, the acetone extract has the highest $\mathrm{IC}_{50}$ value of $4.07 \pm 1.04 \mu \mathrm{g} / \mathrm{ml}$, among $M$. oxyloba extracts, the methanolic extract was the best one with $\mathrm{IC}_{50}$ value of $1.94 \pm 1.84 \mu \mathrm{g} / \mathrm{ml}$, and among M. aegyptia and M. parviflora extracts, the hexane extracts were the best with $\mathrm{IC}_{50}$ values of $6.9 \pm 1.42 \mu \mathrm{g} / \mathrm{ml}$ and $22.9 \pm 1.47 \mu \mathrm{g} / \mathrm{ml}$, respectively.

The ferrous ion chelating activity of the different extracts is mentioned in Table 9. It is interesting to mention that the aqueous extract showed better activity than the other
TABle 2: Absorption values of several concentrations of the standard gallic acid [14].

\begin{tabular}{lc}
\hline $\begin{array}{l}\text { The concentration of } \\
\text { gallic acid }(\mu \mathrm{g} / \mathrm{ml})\end{array}$ & Absorption at $\lambda \max =765 \mathrm{~nm}$ \\
\hline 0.0 & 0.00 \\
10 & 0.14 \\
40 & 0.49 \\
50 & 0.55 \\
70 & 0.79 \\
\hline
\end{tabular}

extracts; the $\mathrm{IC}_{50}$ values were ranged from $52.7 \pm 1.8$ to $95.5 \pm 3.4 \mu \mathrm{g} / \mathrm{ml}$. The hexane extract of different plants was inactive; this might be due to the absence of polar chemical compound which is able to form chelate with the ferrous ion. The acetone extract of the plant exhibited weak activity. The $\mathrm{IC}_{50}$ values ranged from $315.5 \pm 7.0$ to $425.5 \pm 10.2 \mu \mathrm{g} / \mathrm{ml}$. The ferrous ion chelating activity of $M$. sylvestris was better than the other extracts.

3.4. Antimicrobial Capacities. Most of M. sylvestris, M. oxyloba, M. parviflora, and M. aegyptia plants hexane, methanol, acetone, and aqueous extracts exhibited the growth of Staphylococcus aureus, Escherichia coli, Pseudomonas aeruginosa, Shigella sonnei, and Proteus vulgaris at various levels as presented in Table 10.

\section{Discussion}

Over thousands of years, the human orientations towards herbal products have been increasing significantly, for food purposes or for the medicinal use. Millions of people around the world believe in the efficacy and safety of the plants as being a natural resource in many areas of their lives. Many valuable medicines have been derived from plant source such as digoxin, vincristine, pilocarpine, atropine, and many others [17].

In recent years, some groups of natural compounds have received remarkable attention including polyphenols and simple phenols, which are an essential group of secondary metabolites with a wide diversity in structures and are biosynthesized in different parts of the plants for various functions such as protection, pigmentation, and pollination [18]. Various investigations have linked a high phenolic diet to the prevention of several cardiovascular, metabolic, infectious, and cancer diseases due to their pharmacological and biological activities [19].

Total phenolic content of all the plant extracts of all the four species of Malva were estimated using the Folin-Ciocalteu assay. 


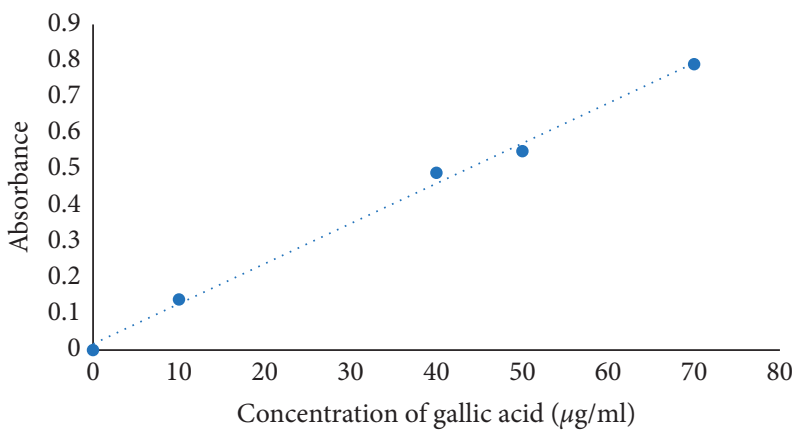

Figure 1: Standard calibration curve of gallic acid for the calculation of total phenols [14].

TABLE 3: Quantitative phenol content of the hexane, acetone, methanol, and aqueous extracts of M. oxyloba, M. aegyptia, M. sylvestris, and M. parviflora.

\begin{tabular}{lcccc}
\hline \multirow{2}{*}{ Extracts } & $\begin{array}{c}\text { Total phenol contents, } \mathrm{mg} \text { of } \\
\text { GAE/g of } M \text {. oxyloba, } \pm \text { SD }\end{array}$ & $\begin{array}{c}\text { Total phenol contents, mg of } \\
\text { GAE/g of } M \text {. aegyptia, } \pm \text { SD }\end{array}$ & $\begin{array}{c}\text { Total phenol contents, mg of } \\
\text { GAE/g of } M \text {. sylvestris, } \pm \text { SD }\end{array}$ & $\begin{array}{c}\text { Total phenol contents, mg of } \\
\text { GAE/g of } M \text {. parviflora, } \pm \text { SD }\end{array}$ \\
\hline Acetone & $12.35 \pm 0.73$ & $25.28 \pm 2.99$ & $104.01 \pm 2.04$ & $27.54 \pm 2.66$ \\
Methanol & $191.54 \pm 2.84$ & $77.58 \pm 2.44$ & $20.47 \pm 1.48$ & $42.44 \pm 2.36$ \\
Hexane & $88.19 \pm 2.79$ & $106.9 \pm 2.22$ & $69.49 \pm 1.15$ & $132.19 \pm 1.97$ \\
Aqueous & $95.5 \pm 2.67$ & $17.11 \pm 2.15$ & $23.35 \pm 0.76$ & $32.95 \pm 1.67$ \\
\hline
\end{tabular}

TABLE 4: DPPH scavenging activity of Trolox and four $M$. parviflora extracts.

\begin{tabular}{lcccccccccc}
\hline Conc. & Trolox & \pm SD & Acetone extract & \pm SD & Methanolic extract & \pm SD & Hexane extract & \pm SD & Aqueous extract & \pm SD \\
\hline 0 & 0 & 0 & 0 & 0 & 0 & 0 & 0 & 0 & 0 \\
1 & 50.72 & 1.06 & 29.85 & 0.63 & 27.3 & 1.13 & 32.8 & 0.42 & 10.3 \\
2 & 51.0 & 0.49 & 36.35 & 1.34 & 32.7 & 0.28 & 32.8 & 0.42 & 31.5 \\
3 & 70.2 & 0.35 & 36.35 & 1.34 & 33.05 & 1.06 & 37 & 0.81 & 32.1 & 0.44 \\
5 & 70.2 & 0.35 & 36.9 & 1.69 & 35.8 & 0.35 & 37.27 & 1.22 & 36.5 \\
7 & 83.95 & 0.21 & 43.1 & 2.2 & 37.7 & 0.98 & 37.27 & 2.4 & 40.0 \\
10 & 95.99 & 1.69 & 43.1 & 1.69 & 37.7 & 0.99 & 37.27 & 2.1 & 40.1 \\
20 & 99.71 & 1.06 & 43.1 & 1.69 & 39.65 & 1.2 & 39.44 & 1.13 & 41.0 \\
30 & 99.71 & 0.49 & 49.2 & 1.55 & 43.1 & 1.99 & 49.95 & 4.32 & 43.2 \\
40 & 99.71 & 0.49 & 55.0 & 1.83 & 44.1 & 2.4 & 54.7 & 0.35 & 52.1 \\
50 & 99.71 & 0.35 & 55.0 & 2.7 & 47.0 & 1.97 & 61.0 & 2.2 & 51.4 \\
80 & 99.71 & 2.25 & 55.0 & 1.64 & 47.8 & 2.6 & 67.5 & 0.85 & 0.65 \\
\hline
\end{tabular}

TABLE 5: DPPH scavenging activity of Trolox and four M. oxyloba extracts.

\begin{tabular}{lcccccccccc}
\hline Conc. & Trolox & \pm SD & Acetone extract & \pm SD & Methanolic extract & \pm SD & Hexane extract & \pm SD & Aqueous extract & \pm SD \\
\hline 0 & 0 & 0 & 0 & 0 & 0 & 0 & 0 & 0 & 0 & 0 \\
1 & 50.72 & 1.06 & 10.23 & 0.34 & 40.7 & 2.22 & 10.23 & 0.37 & 44 & 1.7 \\
2 & 51 & 0.49 & 32.92 & 0.57 & 52.15 & 2.82 & 32.92 & 0.38 & 43.15 \\
3 & 70.2 & 0.35 & 32.9 & 1.12 & 62.25 & 1.5 & 32.9 & 1.5 & 43.35 & 1.5 \\
5 & 70.2 & 0.35 & 35.65 & 0.45 & 85.25 & 1.34 & 35.65 & 0.35 & 51.13 & 1.13 \\
7 & 83.95 & 0.21 & 40.86 & 0.45 & 95.35 & 0.85 & 40.86 & 0.35 & 52.13 \\
10 & 95.99 & 1.69 & 40.86 & 0.39 & 95.35 & 2.22 & 40.86 & 0.52 & 53.13 \\
20 & 99.71 & 1.06 & 42.09 & 0.21 & 96.25 & 1.75 & 51.22 & 1.8 & 52.45 \\
30 & 99.71 & 0.49 & 44.1 & 0.63 & 96.65 & 1.99 & 54.75 & 0.45 & 53.42 \\
40 & 99.71 & 0.49 & 51.18 & 1.45 & 96.65 & 2.11 & 54.75 & 0.63 & 54.42 \\
50 & 99.71 & 0.35 & 51.18 & 0.63 & 96.65 & 2.1 & 65.35 & 0.45 & 55.5 \\
80 & 99.71 & 2.25 & 59.17 & 1.8 & 99.5 & 1.34 & 67 & 1.88 & 1.99 \\
\hline
\end{tabular}

Total phenolic content of $M$. sylvestris, M. oxyloba, M. parviflora, and M. aegyptia plants hexane, methanol, acetone, and aqueous extracts were estimated using the
Folin-Ciocalteu assay. However, the results revealed that the total phenolic contents of these herbal species ranged from $12.35 \pm 0.73$ to $191.54 \pm 2.84 \mathrm{mg} \mathrm{GAE} / \mathrm{g}$. In fact, the methanolic 
TABLE 6: DPPH scavenging activity of Trolox and four M. aegyptia extracts.

\begin{tabular}{lcccccccccc}
\hline Conc. & Trolox & \pm SD & Acetone extract & \pm SD & Methanolic extract & \pm SD & Hexane extract & \pm SD & Aqueous extract & \pm SD \\
\hline 0 & 0 & 0 & 0 & 0 & 0 & 0 & 0 & 0 & 0 \\
1 & 50.72 & 1.06 & 43 & 0.7 & 39.15 & 1.48 & 41.78 & 1.01 & 51.78 & 0.37 \\
2 & 51.21 & 0.49 & 43.25 & 1.2 & 38.8 & 0.98 & 41.78 & 1.38 & 61.78 & 0.38 \\
3 & 70.22 & 0.35 & 43.25 & 1.2 & 44.08 & 1.3 & 41.78 & 1.5 & 71.78 & 1.5 \\
5 & 70.2 & 0.35 & 50.13 & 0.94 & 49.22 & 1.1 & 43.25 & 0.83 & 73.25 & 0.35 \\
7 & 83.95 & 0.21 & 50.13 & 0.94 & 49.22 & 1.1 & 46.71 & 0.83 & 76.71 \\
10 & 95.99 & 1.69 & 50.13 & 0.39 & 49.22 & 2.22 & 46.71 & 0.85 & 76.71 & 0.35 \\
20 & 99.71 & 1.06 & 51.4 & 0.21 & 63.2 & 0.7 & 46.71 & 1.13 & 76.71 \\
30 & 99.71 & 0.49 & 54.4 & 0.84 & 63.85 & 1.99 & 63.5 & 1.27 & 73.5 \\
40 & 99.71 & 0.49 & 54.4 & 0.65 & 64.1 & 1.62 & 77.2 & 1.87 & 77.2 & 0.45 \\
50 & 99.71 & 0.35 & 55 & 2.2 & 80.5 & 1.97 & 94 & 2.2 & 84 \\
80 & 99.71 & 2.25 & 56.84 & 1.66 & 82.45 & 1.34 & 94.32 & 2.71 & 84.32 & 0.45 \\
\hline
\end{tabular}

TABLE 7: DPPH scavenging activity of Trolox and four M. sylvestris extracts.

\begin{tabular}{lcccccccccc}
\hline Conc. & Trolox & \pm SD & Acetone extract & \pm SD & Methanolic extract & \pm SD & Hexane extract & \pm SD & Aqueous extract & \pm SD \\
\hline 0 & 0 & 0 & 0 & 0 & 0 & 0 & 0 & 0 & 0 \\
1 & 50.72 & 1.06 & 43.45 & 0.49 & 19.1 & 2.3 & 30.97 & 0.74 & 10.23 \\
2 & 51 & 0.49 & 43.95 & 0.49 & 24.8 & 0.57 & 33.65 & 0.77 & 32.92 & 0.34 \\
3 & 70.2 & 0.35 & 49.13 & 0.52 & 24.8 & 2.1 & 33.65 & 0.77 & 32.9 & 1.12 \\
5 & 70.2 & 0.35 & 55.8 & 0.28 & 33.5 & 1.1 & 40.71 & 0.68 & 35.65 & 0.45 \\
7 & 83.95 & 0.21 & 63.05 & 1.34 & 37.7 & 1.7 & 40.71 & 2.3 & 40.86 \\
10 & 95.99 & 1.69 & 63.05 & 1.34 & 49.2 & 1.7 & 40.71 & 0.85 & 40.86 \\
20 & 99.71 & 1.06 & 78.15 & 1.48 & 55.7 & 0.99 & 50.65 & 0.49 & 42.09 & 0.39 \\
30 & 99.71 & 0.49 & 83.4 & 1.55 & 78.4 & 1.4 & 52.95 & 0.77 & 44.1 \\
40 & 99.71 & 0.49 & 88.65 & 1.34 & 79 & 1.62 & 56.05 & 0.21 & 51.18 \\
50 & 99.71 & 0.35 & 88.65 & 0.91 & 79.12 & 1.97 & 60.5 & 2.2 & 51.18 \\
80 & 99.71 & 2.25 & 88.65 & 1.66 & 79.12 & 0.88 & 61.5 & 2.83 & 0.63 \\
\hline
\end{tabular}

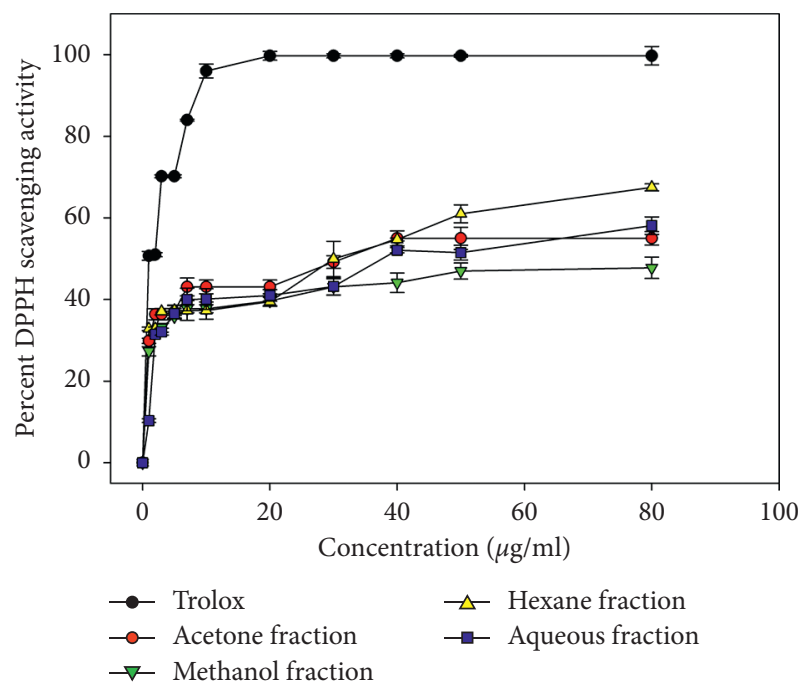

FIgURE 2: DPPH scavenging activity of Trolox (reference compound) and four $M$. parviflora extract.

extract of M. oxyloba showed the highest phenolic content $(191.54 \pm 2.84 \mathrm{mg} \mathrm{GAE} / \mathrm{g})$, followed by the hexane extracts of M. parviflora and M. aegyptia plants $(106.9 \pm 2.22 \mathrm{mg} \mathrm{GAE} / \mathrm{g})$ and (132.19 $\pm 1.97 \mathrm{mg} \mathrm{GAE} / \mathrm{g})$, respectively, and M. sylvestris (104.01 $\pm 2.04 \mathrm{mg} \mathrm{GAE} / \mathrm{g}$ ), whereas $M$. oxyloba acetone extract

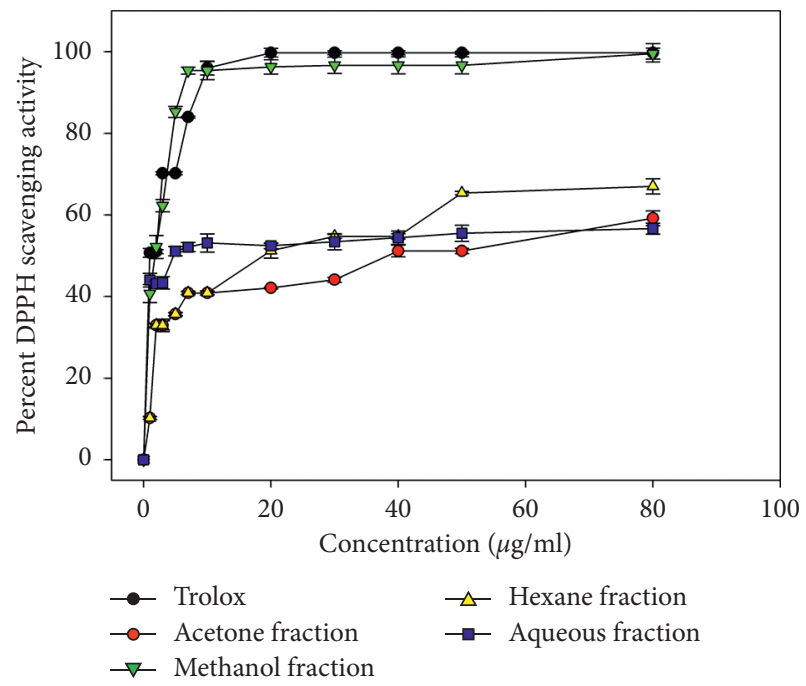

FIgURE 3: DPPH scavenging activity of Trolox (reference compound) and four M. oxyloba extracts.

showed the lowest phenolic content $(12.35 \pm 0.73 \mathrm{mg} \mathrm{GAE} / \mathrm{g})$ among all the extract of these plants.

In a study conducted by Afolayan et al., the total phenolic content in the methanolic extract of $M$. parviflora was $2.9 \pm 0.03 \mathrm{mg} \mathrm{GAE} / \mathrm{g}[20]$. Another study performed by 


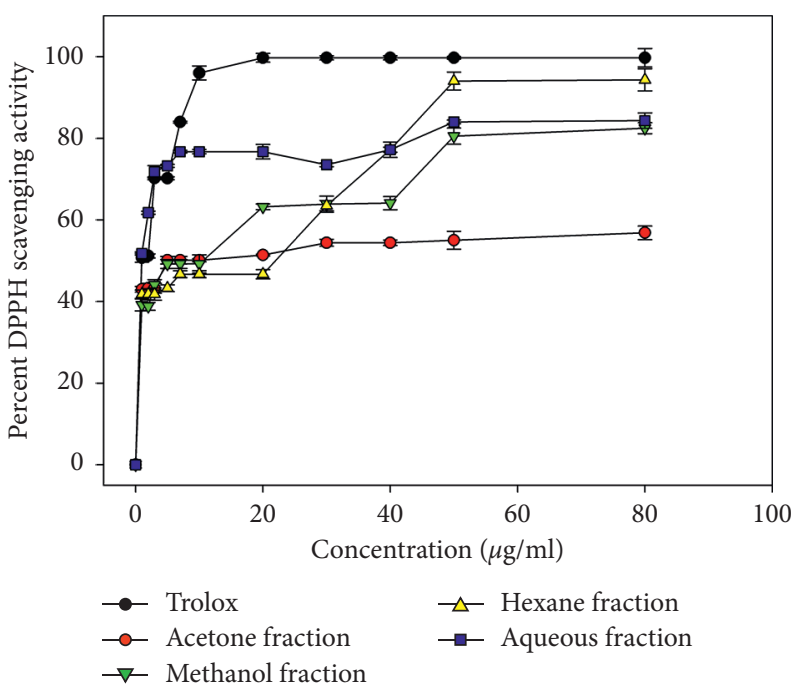

FIGURE 4: DPPH scavenging activity of Trolox (reference compound) and four M. aegyptia extracts.

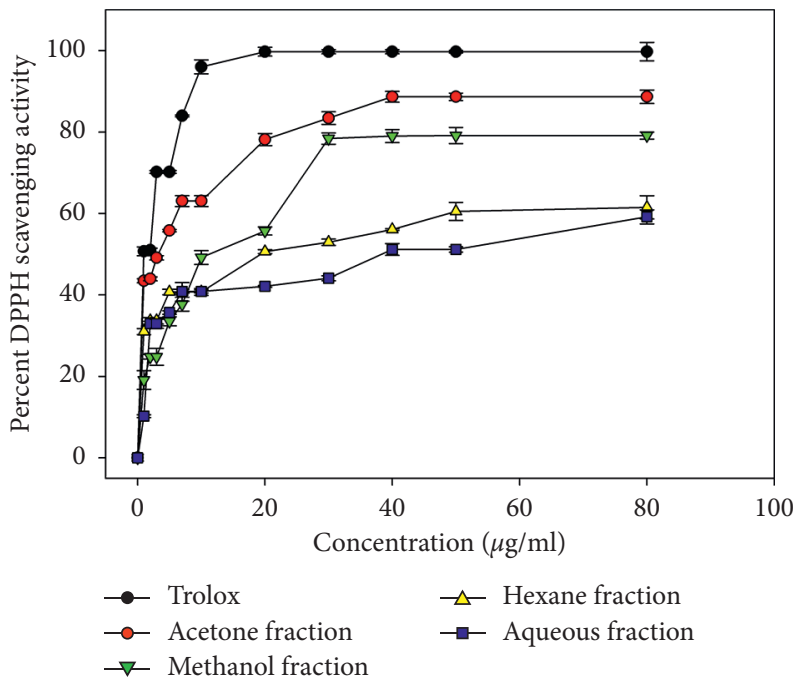

FIGURE 5: DPPH scavenging activity of Trolox (reference compound) and four M. sylvestris extracts.

TABLE 8: DPPH Free radical scavenging antioxidant activity $\left(\mathrm{IC}_{50}\right)$ values.

\begin{tabular}{lccccc}
\hline Extracts & $\begin{array}{c}\mathrm{IC}_{50} \text { values }(\mu \mathrm{g} / \mathrm{ml}), \\
\pm \mathrm{SD} \text { of } M . \text { oxyloba }\end{array}$ & $\begin{array}{c}\mathrm{IC}_{50} \text { values }(\mu \mathrm{g} / \mathrm{ml}), \\
\pm \text { SD of } M \text {. aegyptia }\end{array}$ & $\begin{array}{c}\mathrm{IC}_{50} \text { values }(\mu \mathrm{g} / \mathrm{ml}), \pm \mathrm{SD} \\
\text { of } M . \text { sylvestris }\end{array}$ & $\begin{array}{c}\mathrm{IC}_{50} \text { values }(\mu \mathrm{g} / \mathrm{ml}), \pm \mathrm{SD} \\
\text { of } M \text {. parviflora }\end{array}$ & $\begin{array}{c}\mathrm{IC} C_{50} \text { values }(\mu \mathrm{g} / \mathrm{ml}), \\
\pm S D \text { of Trolox }\end{array}$ \\
\hline Acetone & $32.35 \pm 0.73$ & $15.48 \pm 0.99$ & $4.07 \pm 1.04$ & $27.54 \pm 1.66$ \\
Methanol & $1.94 \pm 1.84$ & $7.58 \pm 1.44$ & $10.47 \pm 1.48$ & $72.44 \pm 1.36$ & $1.86 \pm 0.80$ \\
Hexane & $18.19 \pm 0.79$ & $6.9 \pm 1.42$ & $19.49 \pm 1.15$ & $22.9 \pm 1.47$ & $32.95 \pm 0.67$ \\
Aqueous & $15.5 \pm 0.67$ & $7.11 \pm 2.15$ & $33.35 \pm 0.76$ & \\
\hline
\end{tabular}

$n=3$ individual experiments.

TABLE 9: Ferrous ion chelating activity of extracts $\left(\mathrm{IC}_{50}\right)$ values.

\begin{tabular}{|c|c|c|c|c|c|}
\hline Extracts & $\begin{array}{l}\mathrm{IC}_{50} \text { values }(\mu \mathrm{g} / \mathrm{ml}) \\
\pm \mathrm{SD} \text { of } M . \text { oxyloba }\end{array}$ & $\begin{array}{l}\mathrm{IC}_{50} \text { values }(\mu \mathrm{g} / \mathrm{ml}) \\
\pm \mathrm{SD} \text { of } M . \text { aegyptia }\end{array}$ & $\begin{array}{c}\mathrm{IC}_{50} \text { values }(\mu \mathrm{g} / \mathrm{ml}), \pm \mathrm{SD} \\
\text { of } M . \text { sylvestris }\end{array}$ & $\begin{array}{c}\mathrm{IC}_{50} \text { values }(\mu \mathrm{g} / \mathrm{ml}), \pm \mathrm{SD} \\
\text { of } M . \text { parviflora }\end{array}$ & $\begin{array}{l}\mathrm{IC}_{50} \text { values }(\mu \mathrm{g} / \\
\mathrm{ml}), \pm \text { SD EDTA }\end{array}$ \\
\hline Acetone & $425.5 \pm 10.2$ & $405.1 \pm 3.2$ & $315.5 \pm 7.0$ & $350.0 \pm 6.2$ & \multirow{4}{*}{$12.1 \pm 1.1$} \\
\hline Methanol & $269.1 \pm 6.3$ & $295.2 \pm 5.1$ & $225.2 \pm 4.5$ & $260.2 \pm 8.2$ & \\
\hline Hexane & - & - & - & - & \\
\hline Aqueous & $95.5 \pm 3.4$ & $86.1 \pm 4.7$ & $52.7 \pm 1.8$ & $75.8 \pm 7.4$ & \\
\hline
\end{tabular}

$n=3$ individual experiments. 
TABle 10: Antimicrobial activities (MICs) of the acetone, hexane, and methanolic fractions of Malva species.

\begin{tabular}{|c|c|c|c|c|c|c|c|c|c|c|c|c|c|c|c|c|}
\hline \multirow[t]{2}{*}{ Microorganisms } & \multicolumn{4}{|c|}{ MIC, $\mathrm{mg} / \mathrm{ml}$ acetone extract } & \multicolumn{4}{|c|}{$\begin{array}{c}\text { MIC, mg/ml hexane } \\
\text { extract }\end{array}$} & \multicolumn{4}{|c|}{$\begin{array}{c}\text { MIC, mg/ml methanolic } \\
\text { extract }\end{array}$} & \multicolumn{4}{|c|}{$\begin{array}{c}\text { MIC, } \mathrm{mg} / \mathrm{ml} \text { aqueous } \\
\text { extract }\end{array}$} \\
\hline & MS & MO & MA & MP & MS & $\mathrm{MO}$ & MA & MP & MS & $\mathrm{MO}$ & MA & MP & MS & MO & MA & MP \\
\hline & & & & 25 & - & - & & & & & & & & & & \\
\hline S. $s$ & 125 & 25 & 6.25 & - & $\overline{25}$ & $\overline{25}$ & 0.125 & 12.5 & 12.5 & 3.125 & - & 6.25 & 6.25 & & & 12.5 \\
\hline E. coli & 12.5 & 12.5 & 3.125 & $6 . \overline{2} 5$ & 25 & - & 12.5 & 12.5 & 6.25 & 0.078 & $3 . \overline{125}$ & 25 & 50 & 2 & $1 \overline{2.5}$ & - \\
\hline P. $a$ & 12 & 25 & 6.25 & 12.5 & - & $6 . \overline{2} 5$ & 625 & 6. & 6.25 & 0.78 & 6.25 & 6.2 & - & 1.56 & - & $3 . \overline{125}$ \\
\hline P. vulgaris & 0.078 & 6.25 & 6.25 & 12.5 & - & 12.5 & 12.5 & 6.25 & 12.5 & 6.25 & 25 & 12.5 & $1 \overline{2.5}$ & 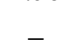 & $6 . \overline{2} 5$ & 3.125 \\
\hline
\end{tabular}

-: no bacterial inhibition, MO:Malva oxyloba, MS: Malva sylvestris, MA:Malva aegyptia, and MP : Malva parviflora.

Tabaraki et al. found that the total phenolic content of M. sylvestris methanolic extract was $15.11 \pm 0.28 \mathrm{mg} \mathrm{GAE} / \mathrm{g}$ [7]. However, another study established by Beghdad et al. showed that the total phenolic content of the M. sylvestris leaves extract was $24.12 \pm 0.72 \mathrm{mg} \mathrm{GAE} / \mathrm{g}$ [21].

In the last two decades, the health benefits of antioxidant molecules obtained from various species of vegetables and plants have become the major focus of the researchers due to the fact that many of these dangerous diseases such as cancer, diabetes, atherosclerosis, and many other stressrelated diseases can be prevented by the appropriate use of these products [22].

Several reports suggest that, due to the side effects, adverse reactions, and possible carcinogenic effects of using chemically synthesized antioxidants, there is a universal agreement that the chemical antioxidants need to be replaced with natural ones. Therefore, the present study aims to explore the antioxidant capacities of the $M$. sylvestris, M. oxyloba, M. parviflora, and M. aegyptia hexane, methanol, acetone, and aqueous extracts. Due to the side effect, adverse reaction, and the possible carcinogenic effect that come along the continuous use of chemically synthesized antioxidants, several reports suggest that there is a universal agreement on the replacement of the chemically synthesized antioxidant with the natural ones. Therefore, the present study was aimed to explore the antioxidant capabilities of the Malva species with various extracts.

In the current study, the antioxidant capacities were estimated using the DPPH scavenging method and comparing the obtained results with a positive control compound Trolox that has $\mathrm{IC}_{50} 1.86 \mu \mathrm{g} / \mathrm{ml}$. The plants, in general, showed high antioxidant activity ranging from $1.94 \pm 1.84$ to $72.44 \pm 1.36 \mu \mathrm{g} / \mathrm{ml}$. Particularly, the methanolic extract of $M$. oxyloba showed the highest antioxidant capacity with $\mathrm{IC}_{50}$ value of $1.94 \pm 1.84 \mu \mathrm{g} / \mathrm{ml}$ among the other methanolic extracts studied; this was followed by the acetone extract of $M$. sylvestris $(4.07 \pm 1.04 \mu \mathrm{g} / \mathrm{ml})$, which had the highest antioxidant activity among the other acetone extracts studied. In addition, the hexane extract of $M$. aegyptia showed the highest antioxidant activity $(6.9 \pm 1.42 \mu \mathrm{g} / \mathrm{ml})$ among the other hexane extracts, and finally, the aqueous extracts of $M$. aegyptia showed the highest antioxidant $(7.11 \pm 2.15 \mu \mathrm{g} / \mathrm{ml})$ among the other aqueous extracts. The lowest antioxidant activity was observed in all the four extracts of M. parviflora. This study shows that methanolic extract of $M$. oxyloba has the $\mathrm{IC}_{50}$ value almost similar to the value of Trolox $(1.86 \mu \mathrm{g} / \mathrm{ml})$, which suggests that this extract can be used as a natural alternative therapy for the prevention and treatment of various degenerative diseases and disorders.

Afolayan and his coworkers reported the $\mathrm{IC}_{50}$ value of $M$. parviflora to be $94.3 \pm 0.03 \mu \mathrm{g} / \mathrm{ml}$ [20]. In another study, Beghdad et al. showed that $M$. sylvestris leaves extract had an antioxidant $\mathrm{IC}_{50}$ value of $16.691 \pm 0.2 \mu \mathrm{g} / \mathrm{ml}$ [21]. This suggests that the results obtained in the present investigation have the highest $\mathrm{IC}_{50}$ values when compared to other studies indicating that the plant species has the highest free radical scavenging activity which may be due to their total phenolic content, and in the present studies, the total phenolic content was the highest among all the reported literatures.

Bacterial resistance to many of the recently used modern antibiotics has becomes a common phenomenon. This has prompted many researchers to look for new chemical from natural origin or plant origin which is safer and effective in overcoming the resistance issue; to study the antimicrobial activity from plant origin, many experts went to study herbal antimicrobial effect trying to solve bacterial resistance problem and to develop new drugs [23].

In the present study, all the four extracts of the Malva species were used to explore the antimicrobial potentials against the five bacterial strains using the broth microdilution method.

In the present study, the antimicrobial activity of M. sylvestris, M. oxyloba, M. parviflora, and M. aegyptia species hexane, methanol, acetone, and aqueous extracts was conducted against five bacterial strains using the broth microdilution method. The results showed that $M$. sylvestris acetone extracts inhibited the bacterial growth with the highest MIC values of $0.125 \mathrm{mg} / \mathrm{ml}$ against $S$. aureus and $0.078 \mathrm{mg} / \mathrm{ml}$ against $P$. vulgaris among the other acetone extracts. In addition, the hexane extract of $M$. aegyptia inhibited the highest growth of bacterial strains among hexane extracts of the other plants with MIC value of $0.125 \mathrm{mg} / \mathrm{ml}$ against $S$. sonnei. Moreover, the methanolic extract of $M$. oxyloba showed the highest antibacterial among the others methanolic extracts with MIC values of 0.078 and $0.78 \mathrm{mg} / \mathrm{ml}$ against E. coli and $P$. aeruginosa, respectively, while the aqueous extracts of $M$. sylvestris, M. oxyloba, M. parviflora, and M. aegyptia showed weak antibacterial activity in comparison with the other plants extracts. In fact, M. sylvestris acetone extract exhibited strong activity against $P$. vulgaris with MIC value of $0.078 \mathrm{mg} / \mathrm{ml}$, while M. oxyloba methanolic extract showed 
appreciable activity against E. coli with MIC value of $0.078 \mathrm{mg} / \mathrm{ml}$.

In a study conducted by Razavi et al. [10], they found that the methanolic extract of M. sylvestris inhibited the growth of Escherichia coli and Staphylococcus aureus with MIC values of 32 and $36 \mathrm{mg} / \mathrm{ml}$, respectively [10]. At the same time, in the present study, the methanolic extract of M. sylvestris inhibited the growth of the Escherichia coli and Staphylococcus aureus with MIC values of 6.25 and $12.5 \mathrm{mg} /$ $\mathrm{ml}$, respectively.

In fact, due to the high phenolic contents of M. sylvestris, M. oxyloba, M. parviflora, and M. aegyptia species, the hexane, methanolic, acetone, and aqueous extracts of these species showed strong antibacterial activities, and several prior researches generally confirm that the phenolic compounds affect strongly the microbial growth [24].

These finding indicated that the acetone extract of $M$. sylvestris and the methanolic extract of M. oxyloba can be used as a suitable candidate in the manufacturing of natural phytoalexins and as a natural alternative to synthetic antibiotics. In line with previous studies, the current study found a strong positive correlation between antioxidant activities of plants extracts and total phenolic content, which implies that the studied plant's phenols are the major contributor to the antioxidant activity in these extracts. Naturally, occurring phenols have an antioxidant activity as these molecules have the ability to scavenge free radicals by a single-electron transfer mechanism which decreases the oxidative stress in life cells and tissues [7].

\section{Conclusion}

In view of the abovementioned results, the methanolic extract of $M$. oxyloba is a pharmacologically valuable natural product that can be utilized as the backbone for the design and development of new therapeutic formulations. It exerts multiple inhibitory properties against oxidative stress and bacterial growth. As such, it represented promising therapeutic agents for the treatment of various neurodegenerative diseases and many types of human infectious diseases.

It may be concluded from our studies that the methanolic extract of the M. oxyloba is of great pharmacological value, as this natural product can be utilized in the design and development of the new therapeutic formulations as the main ingredient. Due to its inhibitory properties against oxidative stress and bacterial growth, it may be one of the promising therapeutic agents to treat various neurodegenerative diseases and many of the infectious diseases in human.

\section{Data Availability}

The data used to support the findings of this study are available within the manuscript.

\section{Conflicts of Interest}

The authors declare that there are no conflicts of interest regarding the publication of this paper.

\section{Acknowledgments}

The authors thank the Dean of the Faculty of Pharmacy and Medical Sciences, Dean, Scientific Research, Al-Ahliyya Amman University, Amman, Jordan, and Dean, Faculty of Medicine and Health Sciences, An-Najah National University, Nablus, Palestine, for providing necessary facilities and support.

\section{References}

[1] M. Ekor, "The growing use of herbal medicines: issues relating to adverse reactions and challenges in monitoring safety," Frontiers in Pharmacology, vol. 4, pp. 177-186, 2014.

[2] S. Tas, B. Tas, N. Bassalat, and N. Jaradat, "In-vivo, hypoglycemic, hypolipidemic and oxidative stress inhibitory activities of Myrtus communis L. fruits hydroalcoholic extract in normoglycemic and streptozotocin-induced diabetic rats," Biomedical Research, vol. 29, pp. 2727-2734, 2018.

[3] N. Jaradat, N. Shawarb, F. Hussein et al., "Antibacterial and antioxidant screening of semi-synthetic naringin based hydrazone and oxime derivatives," Jundishapur Journal of Microbiology, vol. 11, Article ID e65496, 2018.

[4] M.-A. Jabri, D. Wannes, N. Hajji, M. Sakly, L. Marzouki, and H. Sebai, "Role of laxative and antioxidant properties of Malva sylvestris leaves in constipation treatment," Biomedicine \& Pharmacotherapy, vol. 89, pp. 29-35, 2017.

[5] J. C. Gasparetto, C. A. F. Martins, S. S. Hayashi, M. F. Otuky, and R. Pontarolo, "Ethnobotanical and scientific aspects of Malva sylvestris L.: a millennial herbal medicine," Journal of Pharmacy and Pharmacology, vol. 64, no. 2, pp. 172-189, 2012.

[6] P. Dipak, "A review on biological activities of common mallow (Malva sylvestris L.)," Innovare Journal of Life Sciences, vol. 5, pp. 1-5, 2016.

[7] R. Tabaraki, Z. Yosefi, and G. H. A. Asadi, "Chemical composition and antioxidant properties of Malva sylvestris L," Journal of Research in Agricultural Sciences, vol. 8, pp. 59-68, 2012.

[8] W. Zhen-Yu, "Impact of anthocyanin fromMalva sylvestris on plasma lipids and free radical," Journal of Forestry Research, vol. 16, no. 3, pp. 228-232, 2005.

[9] I. Gürbüz, A. M. Özkan, E. Yesilada, and O. Kutsal, "Antiulcerogenic activity of some plants used in folk medicine of Pinarbasi (Kayseri, Turkey)," Journal of Ethnopharmacology, vol. 101, no. 1-3, pp. 313-318, 2005.

[10] S. M. Razavi, G. Zarrini, G. Molavi, and G. Ghasemi, "Bioactivity of Malva sylvestris L., a medicinal plant from Iran," Iranian Journal of Basic Medical Sciences, vol. 14, no. 6, p. 574, 2011.

[11] T. L. Shale, W. A. Stirk, and J. Van Staden, "Variation in antibacterial and anti-inflammatory activity of different growth forms of Malva parviflora and evidence for synergism of the anti-inflammatory compounds," Journal of Ethnopharmacology, vol. 96, no. 1-2, pp. 325-330, 2005.

[12] V. L. Singleton and J. A. Rossi, "Colorimetry of total phenolics with phosphomolybdic-phosphotungstic acid reagents," American Journal of Enology and Viticulture, vol. 16, pp. 144-158, 1965.

[13] L. M. Cheung, P. C. K. Cheung, and V. E. C. Ooi, "Antioxidant activity and total phenolics of edible mushroom extracts," Food Chemistry, vol. 81, no. 2, pp. 249-255, 2003.

[14] N. Jaradat, M. Qneibi, M. Hawash et al., "Chemical composition, antioxidant, antiobesity, and antidiabetic effects of Helichrysum sanguineum (L.) Kostel. from Palestine," 
Arabian Journal for Science and Engineering, vol. 46, no. 1, pp. 41-51, 2021.

[15] S. L. Jothy, A. Aziz, Y. Chen, and S. Sasidharan, "Antioxidant activity and hepatoprotective potential of polyalthia longifolia and cassia spectabilis leaves against paracetamol-induced liver injury," Evidence-Based Complementary and Alternative Medicine, vol. 2012, Article ID 561284, 10 pages, 2012.

[16] M.-T. Chua, Y.-T. Tung, and S.-T. Chang, "Antioxidant activities of ethanolic extracts from the twigs of Cinnamomum osmophloeum," Bioresource Technology, vol. 99, no. 6, pp. 1918-1925, 2008, p.

[17] H. Yuan, Q. Ma, L. Ye, and G. Piao, "The traditional medicine and modern medicine from natural products," Molecules, vol. 21, no. 5, p. 559, 2016.

[18] D. Lin, M. Xiao, J. Zhao et al., "An overview of plant phenolic compounds and their importance in human nutrition and management of type 2 diabetes," Molecules, vol. 21, no. 10, p. 1374, 2016.

[19] S. González, M. Fernández, A. Cuervo, and C. Lasheras, "Dietary intake of polyphenols and major food sources in an institutionalised elderly population," Journal of Human $\mathrm{Nu}$ trition and Dietetics, vol. 27, no. 2, pp. 176-183, 2014.

[20] A. J. Afolayan, O. M. Aboyade, and M. O. Sofidiya, "Total phenolic content and free radical scavenging activity of Malva parviflora L. (Malvaceae)," Journal of Biological Sciences, vol. 8, no. 5, pp. 945-949, 2008.

[21] M. C. Beghdad, C. Benammar, F. Bensalah, F.-Z. Sabri, M. Belarbi, and F. Chemat, "Antioxidant activity, phenolic and flavonoid content in leaves, flowers, stems and seeds of mallow (Malva sylvestris L.) from North Western of Algeria," African Journal of Biotechnology, vol. 13, pp. 59-68, 2014.

[22] A. Rahal, A. Kumar, V. Singh et al., "Oxidative stress, prooxidants, and antioxidants: the interplay," BioMed Research International, vol. 2014, Article ID 761264, 19 pages, 2014.

[23] R. Capita and C. Alonso-Calleja, "Antibiotic-resistant bacteria: a challenge for the food industry," Critical Reviews in Food Science and Nutrition, vol. 53, no. 1, pp. 11-48, 2013.

[24] R. Puupponen-Pimiä, L. Nohynek, C. Meier et al., "Antimicrobial properties of phenolic compounds from berries," Journal of Applied Microbiology, vol. 90, pp. 494-507, 2001. 